\title{
Lymphocyte Dysfunction in Congenital Hypoplastic Anemia
}

\author{
Jonathan L. Finlay, Nasrollah T. Shahidi, Sheldon Horowitz, \\ Wayne Borcherding, and Richard Hong, Department of Pediatrics, \\ Divisions of Hematology/Oncology and Immunology, University of \\ Wisconsin Center for Health Sciences, Madison, Wisconsin 53792
}

A B S TRACT Congenital hypoplastic anemia (Diamond-Blackfan syndrome) is thought to involve the erythropoietic cell line alone. In this study, the evaluation of lymphocyte function in five patients with this syndrome revealed a number of abnormalities.

Peripheral blood $\mathrm{T}$ lymphocyte percentages as assessed by monoclonal antibodies were decreased in three patients. T-helper/T-suppressor cell (OKT4:OKT8) ratios were almost unity in four of the five patients. We usually find a ratio of $2: 1$ in normal populations. Studies of lymphocyte-mediated suppression of lymphoproliferation demonstrated an inability to generate concanavalin A-induced suppressor cells in the same four patients and impaired prostaglandinmediated suppression in two patients. Co-culture studies revealed a $\mathrm{T}$ lymphocyte-mediated suppression of erythropoiesis in a single patient, who also showed suppression of the mixed lymphocyte reaction. The four remaining patients showed no excessive suppressor effects either upon erythropoiesis or lymphoproliferation. These studies demonstrate that in congenital hypoplastic anemia, the cellular defect is not restricted to the erythroid progenitor cells, but extends to the lymphocytes.

\section{INTRODUCTION}

Congenital hypoplastic anemia (the Diamond-Blackfan Syndrome) is considered to be an isolated failure of erythropoiesis presenting in the first months of life as anemia and bone marrow erythroid hypoplasia,

This work was presented in part before the Annual Meeting of the Society of Pediatric Research-American Pediatric Society in San Antonio, TX, May 1980.

Dr. Finlay's present address is the Children's Hospital at Stanford, Palo Alto, CA.

Received for publication 26 January 1980 and in revised form 6 May 1982. without involvement of the lymphoid or myeloid cell lines (1). However, although mild leukopenia has been reported in some patients (2), abnormalities of lymphocyte number and function have not been described previously. Our recent investigations of a patient with congenital hypoplastic anemia and overt immunodeficiency (3) led us to evaluate immunologic function in all of our patients with the Diamond-Blackfan Syndrome.

In this study, we have examined immunologic function concomitantly with investigations of erythropoiesis in five patients with congenital hypoplastic anemia. Our investigations have revealed impaired lymphocyte proliferation and suppressor cell function, indicating that in our patients with this condition, the defect is not restricted to the erythroid series, but may extend to involve the immune system.

\section{METHODS}

\section{Patients}

Five patients with proven Diamond-Blackfan Syndrome were included in the study. Their ages at study ranged from 2 to $20 \mathrm{yr}$; however, they had all presented within the first year of life, with a profound hypoproliferative anemia shown on bone marrow aspiration to involve solely the erythroid series. Their hemoglobin concentrations at study ranged from 11.0 to $13.4 \mathrm{~g} / \mathrm{dl}$. Three of the patients, A.F., J.St., and S.W., have been off prednisone therapy for 1,3 , and $17 \mathrm{yr}$, respectively. Two patients were still on prednisone at the time of study; patient E.D., $2.5 \mathrm{mg} / \mathrm{wk}$ and patient J.Sc., 5 mg on alternate days.

Three of the patients had never received blood transfusions, while two had received up to three transfusions early in the course of their disease (patients J.Sc. and J.St.). None of the patients had shown any particular susceptibility to infections. No patients had clinical evidence of autoimmune disorders, and fluorescent antibody screening for antinuclear, smooth muscle, mitochondrial, and parietal cell antibodies was negative. None of the patients showed evidence of adenosine deaminase or nucleoside phosphorylase deficiencies, as determined by appropriate enzyme screening 
(4). There were no family histories of either hematologic or immunologic disorders. All patients were studied on at least two occasions from 20 to 21 mo apart.

\section{Mononuclear cell separation}

Peripheral blood and bone marrow were drawn into heparinized syringes from patients and young healthy adult volunteers who had given informed consent. Mononuclear cells were separated from the samples on a Ficoll-Hypaque density gradient, washed twice in phosphate-buffered saline $(\mathrm{PBS})^{1} \mathrm{pH} 7.2$, and suspended in appropriate culture media (see below).

T lymphocyte-enriched mononuclear cell populations were obtained by centrifuging sheep erythrocyte-rosetting T lymphocytes over a Ficoll-Hypaque density gradient. The erythrocytes were removed from the pelleted T lymphocyte rosettes by lysis with distilled water.

\section{Lymphocyte enumeration}

Peripheral blood T lymphocytes were enumerated by their ability to spontaneously form rosettes with sheep erythrocytes (5) as well as their reactivity with fluoresceinated OKTseries monoclonal anti-T cell antibodies. Peripheral blood B lymphocytes were enumerated by their ability to spontaneously form rosettes with mouse erythrocytes (6). B lymphocytes were also identified by staining with fluoresceinated or rhodaminated $F\left(a^{\prime}\right)_{2}$ goat antiheavy chain specific antisera (7). Absolute lymphocyte counts were derived from the total leukocyte and differential counts.

\section{Mitogen-induced lymphocyte proliferation}

Proliferative responses of peripheral blood mononuclear cells to nonspecific plant lectin mitogens were measured in microtiter plates by culturing 100,000 patient cells (in a total volume of $250 \mu$ l in RPMI medium containing $20 \%$ normal pooled plasma) either alone or in the presence of concanavalin A (Con A, $5 \mu \mathrm{g} /$ culture, Calbiochem-Behring Corp., American Hoechst Corp., San Diego, CA), phytohemagglutinin (PHA, $1 \mu \mathrm{g} /$ culture, Burroughs Corp., Detroit, MI) or pokeweed mitogen (PWM, $10 \mu \mathrm{g} /$ culture, Gibco Laboratories, Grand Island Biological Co., Grand Island, NY), for periods of $72 \mathrm{~h}$, followed by pulsing with $\left[{ }^{3} \mathrm{H}\right]$ thymidine $(2$ $\mathrm{Ci} / \mathrm{mmol}$ thymidine, sp act) for $18 \mathrm{~h}$. The results are expressed as net counts per minute obtained by subtracting the counts per minute of parallel cultures containing no proliferative stimulus.

\section{Antigen-stimulated lymphocyte proliferation}

Proliferative responses of peripheral blood mononuclear cells to three specific antigens, tetanus toxoid (1:50 dilution, Wyeth Laboratories, Marietta, PA), streptokinase/streptodornase (1:50 dilution, Lederle Laboratories, Pearl River, NY) and candida antigen (1:50 dilution, Hollister-Stier Laboratories, Inc., Spokane, WA) were measured in microtiter

\footnotetext{
${ }^{1}$ Abbreviations used in this paper: BFU-E, erythroid burst-forming units; CFU-E, erythroid colony-forming units; CFU-TL, T lymphocyte colony-forming units; MLR, mixed lymphocyte reaction; PBS, phosphate-buffered saline; PHA, phytohemagglutinin; PWM, pokeweed mitogen.
}

plates by culturing 100,000 patient cells (in a total volume of $200 \mu \mathrm{l}$ in RPMI medium containing $25 \%$ normal pooled plasma) either alone or in the presence of each antigen for a period of $6 \mathrm{~d}$, followed by pulsing with $\left[{ }^{3} \mathrm{H}\right]$ thymidine for $18 \mathrm{~h}$. Results are expressed as net counts per minute as for mitogen-induced proliferation.

\section{Proliferative response to allogeneic cells (mixed lymphocyte reaction)}

The ability of patient lymphocytes to respond to normal allogeneic cells of both sexes was assessed in a one-way mixed lymphocyte reaction (MLR), performed in microtiter plates (in a total volume per culture of $200 \mu \mathrm{l}$ in RPMI medium containing $25 \%$ normal pooled plasma), using 200,000 normal mononuclear cells irradiated at $2,500 \mathrm{rad}$ as stimulators, and 100,000 patient mononuclear cells as responders, co-cultured for $6 \mathrm{~d}$, followed by pulsing for $18 \mathrm{~h}$ with $\left[{ }^{3} \mathrm{H}\right]$ thymidine. As above, net counts per minute of the stimulated cultures are reported.

\section{Suppression of lymphocyte proliferation}

Prostaglandin-induced suppressor system. This was determined by measuring the proliferative response of patient lymphocytes to PHA in the presence of the prostaglandinsynthetase inhibitor, indomethacin (8). Briefly, 100,000 patient mononuclear cells were incubated with $1 \mu \mathrm{g}$ PHA in microtiter wells for $72 \mathrm{~h}$ with or without $0.25 \mu \mathrm{g}$ indomethacin. Incorporation of $\left[{ }^{3} \mathrm{H}\right]$ thymidine was measured after pulsing for $18 \mathrm{~h}$. Increased incorporation in the presence of indomethacin reflects removal of suppressor activity; the greater the increase in incorporation, the greater the original suppressor activity. Thus, this is an indirect assay of suppressor activity.

Con A-induced suppressor system (8). This was determined in a direct assay as follows. Patient peripheral blood mononuclear cells were incubated for $40 \mathrm{~h}$ at $5 \times 10^{6}$ cells/ $\mathrm{ml}$ in the presence or absence of $60 \mu \mathrm{g}$ of Con A. Following incubation, 100,000 cells, washed three times with PBS, and irradiated at 2,500 rad, were added to a one-way MLR consisting of 100,000 normal responder cells and 100,000 irradiaied $(2,500 \mathrm{rad})$ allogeneic normal stimulator cells. After $5 \mathrm{~d}$ incubation, $\left[{ }^{3} \mathrm{H}\right]$ thymidine incorporation was measured after an $18-\mathrm{h}$ pulse. A decreased $\left[{ }^{3} \mathrm{H}\right]$ thymidine incorporation in the responder cells in the presence of Con Aincubated patient cells, when compared with the incorporation in the responder cells in the presence of patient cells previously cultured in the absence of Con $A$, gives a measure of Con A-induced suppression.

Adherent cell suppressor system (8). In this system, the effect of 800,000 fresh irradiated $(2,500 \mathrm{rad})$ patient mononuclear cells as stimulators in a one-way MLR to 100,000 normal responder cells is compared with the effect of 200,000 fresh irradiated patient cells acting as stimulators in an identical system. The fourfold increase in stimulator population results in a decreased $\left[{ }^{3} \mathrm{H}\right]$ thymidine incorporation in normal individuals, which has been shown to be due to the suppressive effect of an adherent, radioresistant mononuclear cell.

Native, or natural suppressor system. In this system, the effects of fresh irradiated $(2,500 \mathrm{rad})$ patient mononuclear cells upon a one-way MLR is compared with the effect of fresh irradiated allogeneic normal cells in an identical MLR. Briefly, 100,000 fresh irradiated patient mononuclear cells were incubated with 100,000 normal responder cells $\left(N_{1}\right)$ 
and 100,000 irradiated allogeneic normal stimulator cells $\left(\mathrm{N}_{2}\right)$ for $6 \mathrm{~d} ;\left[{ }^{3} \mathrm{H}\right]$ thymidine incorporation was then measured after an 18-h pulse. The incorporation is compared with that produced in a control incubation consisting of 100,000 normal responders $\left(\mathrm{N}_{1}\right), 100,000$ irradiated allogeneic normal stimulators $\left(\mathrm{N}_{2}\right)$ and 100,000 fresh irradiated autologous normal responder cells $\left(\mathrm{N}_{1}\right)$. The cell responsible for suppression in this system has been identified as an adherent, esterasepositive, phagocytic mononuclear cell.

\section{T Lymphocyte colony-forming assay}

The assay used in these studies was that of Lowenberg and De Zeeuw (9), adapted to multi-well culture dishes. Briefly, peripheral blood mononuclear cells were cultured in quadruplicate (at $1 \times 10^{5}$ cells $/ 0.1 \mathrm{ml}$ ) in the presence of 0.3 $\mu \mathrm{g}$. PHA above a $0.5-\mathrm{ml}$ semisolid underlayer of $0.5 \%$ agar containing either no cells or $5 \times 10^{5}$ patient or normal mononuclear cells. The culture medium in both the liquid upper layer and the semisolid "feeder" layer was Eagle's medium containing $10 \%$ horse serum, $10 \%$ newborn calf serum, and $10 \%$ trypticase soy broth. After $6 \mathrm{~d}$ of incubation at $37^{\circ} \mathrm{C}$ in $5 \% \mathrm{CO}_{2}$ with humidification, colonies in the upper layer were counted under a stereomicroscope. Colonies with $>20$ cells along their perimeter were scored. Gentle washing of the colonies from the liquid layer, and assessment by sheep and mouse erythrocyte rosetting, demonstrated $>75 \%$ sheep erythrocyte-rosettable cells and $<1 \%$ mouse erythrocyte-rosettable cells in all plates tested.

\section{Erythroid colony-forming assay}

Bone marrow mononuclear cells were cultured at $2 \times 10^{5}$ cells per milliliter in the presence of 2 IU per milliliter human urinary erythropoietin (prepared by Dr. Peter Dukes and provided by Dr. Anne Ball, Blood Diseases and Re- sources Branch, National Heart, Lung, and Blood Institute, National Institutes of Health, Bethesda, MD) in a semisolid medium of $0.8 \%$ methylcellulose at $37^{\circ} \mathrm{C}$ in $5 \% \mathrm{CO}_{2}$ with humidification (10). After $7 \mathrm{~d}$ in culture, erythroid colonies (CFU-E) were enumerated following staining with benzidine hydrochloride; eight or more cells in a cluster were scored as a colony. The effect of patient peripheral blood mononuclear cells and cell subpopulations upon syngeneic or allogeneic normal bone marrow erythroid colony growth was also studied in all five patients, by mixing the cell populations together before addition to the culture system. In all studies, $1 \times 10^{5}$ peripheral blood mononuclear cells were co-cultured with $2 \times 10^{5}$ bone marrow cells.

\section{RESULTS}

Lymphocyte enumeration. In Table I, the total leukocyte and differential counts are detailed. No consistent significant abnormalities in the total leukocyte counts, the total lymphocyte counts, or the total T lymphocyte counts (as enumerated by sheep erythrocyte rosetting) were found in any of our five patients. Total leukocyte counts were low on at least one occasion in two patients $\left(2,800\right.$ and $\left.3,900 / \mathrm{mm}^{3}\right)$; however, both of these individuals had normal total leukocytes at the other time tested. Absolute lymphocyte counts were low in three instances; again, this was not a constant finding. Similarly, T lymphocyte percentages were low in three when initially tested, but a repeat determination showed normal values. However a striking finding was demonstrated by the use of monoclonal anti $T$ cell antibodies. Low percentages of OKT3 reactive cells were noted in four of the five patients, despite

TABLE I

Lymphocyte Numbers

\begin{tabular}{|c|c|c|c|c|c|c|c|c|c|c|c|}
\hline & \multicolumn{2}{|c|}{ E.D. } & \multicolumn{2}{|c|}{ J.Sc. } & \multicolumn{2}{|c|}{ J.St. } & \multicolumn{2}{|c|}{ s.w. } & \multicolumn{2}{|c|}{ A.F. } & \multirow[b]{2}{*}{ Normals• } \\
\hline & $\mathbf{A}$ & B & $A$ & B & $\mathbf{A}$ & B & $\mathbf{A}$ & B & $\mathbf{A}$ & B & \\
\hline Total leukocyte $/ \mathrm{mm}^{3}$ & 7,200 & 7,100 & 2,800 & 4,700 & 6,000 & 3,900 & 4,800 & - & 6,900 & 7,300 & $4,300-10,000$ \\
\hline Lymphocyte count $/ \mathrm{mm}^{3}$ & 2,088 & 1,775 & 1,070 & 3,102 & 600 & 1,053 & 1,536 & - & 1,967 & 2,263 & $1,500-4,000$ \\
\hline T lymphocytes (ER)\% & 45 & 53 & 74 & 74 & 37 & 65 & 62 & 55 & 25 & 78 & $50-65 \%$ \\
\hline OKT3\% & ND & 45 & ND & 64 & ND & 45 & ND & 14 & ND & 51 & $50-65 \%$ \\
\hline OKT4\% & ND & 29 & ND & 28 & ND & 29 & ND & 8 & ND & 25 & $25-45 \%$ \\
\hline OKT8\% & ND & 20 & ND & 11 & ND & 20 & ND & 6 & ND & 24 & $5-25 \%$ \\
\hline OKT4:OKT8\% & & 1.4 & & 2.5 & & 1.4 & & 1.3 & & 1 & $5-8 \%$ \\
\hline B lymphocytes (MR)\% & 3 & 7 & 5 & 1 & 6 & 4 & 4 & 7 & 1 & 6 & $4-12 \%$ \\
\hline B lymphocytes (SIg+)\% & 2 & 13 & 4 & ND & 16 & 5 & 10 & 11 & 4 & 2 & $2-11 \%$ \\
\hline
\end{tabular}

$A=$ values at time of original investigation.

$B=$ values 20-21 mo later.

ER = sheep erythrocyte rosetting

MR = mouse erythrocyte rosetting.

SIg = surface immunoglobulin fluorescence $(\mathrm{mu}+$ alpha + gamma chains) .

- Normal data in our own laboratory are similar to those widely reported in the literature. These normal values are based on 253 analyses. 10 patients on alternate day prednisone therapy (5-10 mg every other day) for diseases such as rheumatoid arthritis, asthma, and nephrosis showed values within this range. 
TABLE II

Lymphocyte Proliferative Responses to Mitogens, Antigens, and Allogeneic Cells

\begin{tabular}{|c|c|c|c|c|c|c|c|c|c|c|c|}
\hline \multirow[b]{2}{*}{ Patients } & \multicolumn{2}{|c|}{ E.D. } & \multicolumn{2}{|l|}{ J.Sc. } & \multicolumn{2}{|c|}{ J.St. } & \multicolumn{2}{|c|}{ s.w. } & \multicolumn{2}{|c|}{ A.F. } & \multirow[b]{2}{*}{ Normal } \\
\hline & A & B & A & B! & $\mathbf{A}$ & B & A & B & A & B & \\
\hline PHA & $162,895^{\circ}$ & 98,328 & 107,054 & & 110,970 & 147,628 & 184,135 & 221,055 & 111,000 & 311,097 & $51,009-281,180$ \\
\hline Con A & 113,355 & 108,015 & 27,731 & & 54,717 & 67,275 & 91,521 & 98,225 & 46,721 & 127,741 & $15,873-223,767$ \\
\hline PWM & 35,171 & 82,877 & 22,665 & & 21,329 & 23,471 & 28,426 & 33,202 & 9,525 & 29,738 & $5,333-98,265$ \\
\hline Candida & 49,937 & 24,611 & 71,682 & & 35,793 & 7,430 & 925 & 3,790 & 8,775 & 18,039 & $4,802-71,273$ \\
\hline Tetanus toxoid & 38,558 & 30,033 & 24,506 & & 20,725 & 21,380 & 23,607 & 947 & 13,016 & 24,953 & $4,802-71,273$ \\
\hline $\begin{array}{l}\text { Streptokinase, } \\
\text { streptodornase }\end{array}$ & 1,865 & 10,837 & 17,723 & & 16,462 & 7,895 & 24,141 & 495 & 1,288 & 3,455 & $4,802-71,273$ \\
\hline MLR (male stim) & 15,171 & 29,642 & 19,599 & & 12,575 & 23,537 & 31,061 & 38,752 & 55,194 & 42,978 & $7,684-8,100$ \\
\hline MLR (female stim) & 11,718 & 20,741 & 17,243 & & 20,118 & 18,118 & 35,399 & 42,673 & 28,394 & 48,233 & \\
\hline
\end{tabular}

$A=$ values at time of original investigation

$B=$ values $20-21$ mo later.

- Net counts per minute; the number of counts per minute obtained in the stimulated culture minus the counts per minute obtained from an identical culture to which a stimulus is not added.

£ Proliferative responses could not be done due to low lymphocyte recovery.

normal numbers of E-rosettes. Additionally, the normal ratio of OKT $4+$ cells to OKT $8+$ cells $(2: 1)$ was not seen. B lymphocytes as enumerated by surface immunoglobulin fluorescence were normal. However, two patients did show a low number of mouse-rosettable B cells on one of two occasions only.

Lymphocyte proliferation. As shown in Table II, proliferative responses to mitogens (PHA, Con A, PWM) and allogeneic cells were essentially normal.
Suppression of lymphocyte proliferation (Table III). In the prostaglandin-mediated suppressor assay, the presence of a suppressor of PHA-induced lymphoproliferation is demonstrated indirectly by blocking the suppressor with indomethacin. Thus, the increased PHA response in the presence of indomethacin reflects abolition of the suppressor. This suppressor cell is usually demonstrated in normal peripheral blood mononuclear cells, with indomethacin producing an

TABLE III

Assays for Suppression of Lymphoproliferation

\begin{tabular}{|c|c|c|c|c|c|c|c|}
\hline Assay & Patient & E.D. & J.Sc. & J.St. & S.w. & A.F. & Normal \\
\hline $\begin{array}{l}\text {-Prostaglandin-induced } \\
\text { suppressor assay }\end{array}$ & $-10 \%(+4)$ & & $+26 \%$ & $+9 \%(+44)$ & $+17 \%(22)$ & $+3 \%(-15)$ & $>+20$ \\
\hline $\begin{array}{l}\text { tCon A-induced } \\
\text { suppressor assay }\end{array}$ & $+2 \%$ & & ND & $+25 \%$ & $+12 \%$ & $+52 \%$ & $<-40 \%$ \\
\hline $\begin{array}{l}\S \text { Adherent cell } \\
\text { suppressor assay }\end{array}$ & $-77 \%$ & & $-79 \%$ & $-96 \%$ & $-75 \%$ & $-76 \%$ & $<-60 \%$ \\
\hline $\begin{array}{l}\text { "Natural or native } \\
\text { suppressor assay }\end{array}$ & $-29 \%$ & & $+3 \%$ & $+9 \%$ & $+12 \%$ & $+5 \%$ & $0 \%$ \\
\hline
\end{tabular}

- The prostaglandin-induced suppressor assay measures the proliferative response of lymphocytes to PHA in the presence of the prostaglandin synthetase inhibitor, indomethacin. Four patients showed either a reduction or absence of this suppressor cell population. Numbers in parentheses are repeat tests performed 20-21 mo later.

\ The Con A-induced suppressor assay measures the ability of lymphocytes, upon preincubation with Con A for $40 \mathrm{~h}$, to suppress an allogeneic MLR. All four patients studied demonstrated a total inability to generate such suppressor cells.

\$ The adherent cell suppressor assay measures the ability of a population of patient cells to impair the patient's own stimulatory capacity in an MLR. This was normal in all patients.

"The native or natural suppressor assay measures the ability of fresh patient cells to suppress an allogeneic MLR. This ability, not normally present, was detected in a single patient (E.D.). 
increased $\left[{ }^{3} \mathrm{H}\right]$ thymidine incorporation of at least $20 \%$ $(+20 \%)$ in our laboratory. The prostaglandin-mediated suppressor was absent in two of our patients $(-10$ and $+3 \%)$ and reduced in two $(+9$ and $+17 \%)$. When retested, three of four showed persistence of decreased suppressor activity. The Con A-induced suppressor is strongly present in normal peripheral blood mononuclear cells, suppressing the one-way MLR by at least $40 \%(-40 \%)$. However, in all four of the patients tested, there was an absence of the Con A-induced suppressor, with their cells actually eliciting helper effects on the MLR of from +2 to $+52 \%$.

The adherent cell suppressor is normally strongly present in peripheral blood mononuclear cells, suppressing the responder cells in the MLR by at least $60 \%(-60 \%)$. This suppressor was found to be present to a normal degree in all five of our patients $(-75$ to $-96 \%)$.

The native, or natural, suppressor is not normally present in peripheral blood mononuclear cells. However, one of our five patients (E.D.) demonstrated a strong native suppressor of $-29 \%$.

T Lymphocyte colony cultures. These studies were performed upon only two of our patients, patients E.D. and S.W., each on single occasions only. Table IV describes the results of culturing patient and normal cells in the presence of PHA above a feeder layer that was either cell free or containing syngeneic or allogeneic mononuclear cells. Studies on patient E.D. demonstrated a markedly reduced ability to form $\mathrm{T}$ lymphocyte colonies in culture, which could be overcome by the presence of normal mononuclear cells in the feeder layer. However, T lymphocyte colony growth by normal mononuclear cells was markedly reduced in the presence of patient mononuclear cells in the feeder layer.

Studies on patient S.W. demonstrated an unimpaired ability to form $T$ lymphocyte colonies in culture. Further, $T$ colony growth by normal mononuclear cells was not inhibited in the presence of patient mononuclear cells in the feeder layer.

Erythroid colony cultures. Culture of the patients' bone marrow mononuclear cells in the presence of human urinary erythropoietin produced markedly reduced number of CFU-E colonies after $7 \mathrm{~d}$ in culture (10-40\% of simultaneously cultured normal bone marrows) (Table $\mathrm{V}$ ).

Upon co-culture of patient peripheral blood mononuclear cells and cell subpopulations ( $T$ enriched and $T$ depleted) with normal bone marrow, suppressive effects upon normal bone marrow erythroid colony growth were demonstrated only in patient E.D. The results of studies in this patient are summarized in Table VI.

TABLE IV

T Lymphocyte Colony Growth in CHA

\begin{tabular}{|c|c|c|c|}
\hline & \multicolumn{3}{|c|}{ Feeder layer peripheral blood mononuclear cells } \\
\hline & No. cells & Normal cells & Patient cells \\
\hline $\begin{array}{l}\text { PHA-stimulated } \\
\text { Peripheral blood } \\
\text { Mononuclear cells }\end{array}$ & CFU-TL $/ 10^{5}$ cells & CFU-TL $/ 10^{5}$ cells & CFU-TL $/ 10^{5}$ cells \\
\hline Normal & $\begin{array}{l}31 \pm 11.6 \\
P<0.005\end{array}$ & $\begin{array}{r}26 \pm 10.5 \\
P=\mathrm{NS}\end{array}$ & $\begin{array}{l}1 \pm 0.7 \\
P=\mathrm{NS}\end{array}$ \\
\hline Patient E.D. & $7 \pm 1.3$ & $35 \pm 8.7$ & $2 \pm 1.7$ \\
\hline Normal & $\begin{array}{l}34 \pm 5.0 \\
\quad P=\mathrm{NS}\end{array}$ & $\begin{array}{l}32 \pm 8.5 \\
\quad P=\mathrm{NS}\end{array}$ & $\begin{array}{l}28 \pm 2.8 \\
\quad P=\mathrm{NS}\end{array}$ \\
\hline Patient S.W. & $21 \pm 2.2$ & $21 \pm 3.7$ & $19 \pm 4.7$ \\
\hline Normal laboratory values & $27 \pm 9.5$ (5 normals) & $26 \pm 6.8$ (7 normals) & \\
\hline
\end{tabular}

$1 \times 10^{5}$ normal or patient peripheral blood mononuclear cells were cultured in quadruplicate with $0.3 \mu \mathrm{g}$ PHA over a feeder layer of $0.5 \%$ agar containing either no cells or $5 \times 10^{5}$ irradiated peripheral blood mononuclear cells. Colonies were enumerated after $6 \mathrm{~d}$ in culture. As compared with normal values for our laboratory, patient E.D. grew statistically fewer colonies when cultured without feeder cells or with autologous feeder cells $(P<0.001)$. However, colony growth was significantly increased $(P<0.001)$ in the presence of allogeneic normal feeder cells. Further, his own cells, when serving as feeder cells, significantly suppressed normal $\mathrm{T}$ lymphocyte colony growth $(P<0.001)$.

In patient S.W., CFU-TL were unaltered by the presence or absence of autologous or allogeneic normal feeder cells. Further, her cells, serving as feeder cells, did not suppress normal CFU-TL growth. CFU-TL values represent mean \pm 1 SD of quadruplicate cultures. 
TABLE V

Erythroid Colony Growth in Five Patients with Congenital Hypoplastic Anemia

\begin{tabular}{lccc}
\hline & \multicolumn{3}{c}{ CFU-E $/ 2 \times 10^{5}$ cells } \\
\cline { 2 - 4 } Patients & Patient & Normal & \% of normal \\
\hline E.C. & $6 \pm 2$ & $27 \pm 3$ & $22 \%$ \\
J.St. & $3 \pm 2$ & $30 \pm 2$ & $10 \%$ \\
S.W. & $6 \pm 2$ & $30 \pm 2$ & $20 \%$ \\
J.Sc. & $6 \pm 3$ & $50 \pm 8$ & $12 \%$ \\
A.F. & $36 \pm 12$ & $91 \pm 19$ & $40 \%$ \\
\hline
\end{tabular}

$2 \times 10^{5}$ normal bone marrow mononuclear cells were grown in methylcellulose cultures containing $2 \mathrm{U}$ human urinary erythropoietin. Each patient was studied simultaneously with a normal control bone marrow culture. CFU-E values represent means of duplicate cultures. While normal CFU-E growth varied widely (from 27 to 91 mean colonies), the patient CFU-E growth obtained was between 10 and $40 \%$ of the simultaneously studied controls.

\section{DISCUSSION}

We have demonstrated lymphocyte abnormalities in patients whose primary disorder involves erythropoiesis. Obviously, the lymphocyte abnormalities observed are not of sufficient magnitude to cause unusual susceptibility to infections in these patients. Low numbers of T lymphocytes, as measured by OKT3 monoclonal antibodies, were found in three patients. A striking abnormality, however, was the reduction in the ratio of $\mathrm{T}$ helper to $\mathrm{T}$ suppressor cells (OKT4:OKT8). In our laboratory, as well as in others, this ratio is normally $2: 1$. However, in four of our patients, this ratio approached unity.

Functional assessments revealed further abnormalities. All four patients tested demonstrated a complete inability to generate Con A-induced suppressor cells; these suppressor cells have been shown to be $\mathrm{T}$ lymphocytes (11) and are present in normal individuals (8). Although absence of this capability has previously been reported in systemic lupus erythematosus (11), no evidence of any autoimmune disturbance was found in any of our patients. Two of the patients displayed consistently impaired or absent prostaglandin-induced suppression. The finding of altered suppressor cell functions in the face of a relatively high percentage of OKT8+ $\mathrm{T}$ suppressor cells highlights the subtle nature of the lymphocyte abnormalities. The necessity of correlating counting assays with functional tests is illustrated by these results. Another possibility is that the OKT distribution reflects a modest helper inadequacy. The exact reasons for this abnormal ratio of OKT4:OKT8 remains unknown. It is of interest to note, however, that in the same four patients with abnormal OKT4:OKT8 ratios, there was also an inability to generate Con A-induced suppressor cells.

These results could suggest $(a)$ that there is a regulatory defect involving suppressor mechanisms or a relative helper deficiency, or $(b)$ that there is an intrinsic proliferative defect. Additional studies, described below, revealed that each of these patterns of immunologic dysfunction appear to exist in our patients.

Patient E.D. seemed to show excessive suppression mediated by two cell lines. Specifically, he possessed

TABLE VI

Suppression of Erythroid Colony Growth in Patient E.D.

\begin{tabular}{llccc}
\hline \multicolumn{1}{c}{ Normal bone marrow } & \multicolumn{1}{c}{ Patient peripheral blood } & $\begin{array}{c}\text { CFU-E/ } \\
2 \times 10^{5} \text { cells }\end{array}$ & \% Suppression & $P$ Value \\
\hline Normal BM mononuclear cells alone & & 80 & & \\
Normal BM mononuclear cells + & Patient MNC & 42 & $47 \%$ & $<0.02$ \\
Normal BM mononuclear cells + & Patient MNC, irradiated 2,000 rads & 76 & $5 \%$ & 0.5 \\
Normal BM mononuclear cells + & Patient MNC, T cell depleted & 67 & $16 \%$ & 0.21 \\
Normal BM mononuclear cells + & Patient MNC, T cell enriched & 24 & $70 \%$ & $<0.02$ \\
Normal BM mononuclear cells + & Patient fresh plasma & 83 & 0 & \\
\hline
\end{tabular}

- Mononuclear cells.

$2 \times 10^{5}$ normal bone marrow mononuclear cells were grown either alone or in the presence of $1 \times 10^{5}$ patient peripheral blood mononuclear cells, in methylcellulose cultures containing 2 U human urinary erythropoietin. Patient E.D. peripheral blood mononuclear cells suppressed normal bone marrow CFU-E by $47 \%$. However, this suppression was lost if the patient cells were first irradiated at 2,000 rads. The patient's $T$ lymphocyte-depleted population (by sheep erythrocyte rosetting) was not significantly suppressive, whereas the T-enriched population suppressed bone marrow CFU-E by $70 \%$. The patient's fresh plasma, at a concentration of $10 \%$ in the culture, was not suppressive. The effect of normal peripheral blood mononuclear cells upon allogeneic normal bone marrow erythroid growth was studied simultaneously, using cell treatments and subpopulations as above; no suppressive effects were seen $(P>0.2$ in all cultures). CFU-E values represent means of duplicate culture plates. 
a monocyte-mediated suppressor of the MLR (not present in normal individuals). Suppression of $T$ lymphocyte colony growth was also demonstrated. Finally, T lymphocyte-mediated suppression of erythropoiesis was shown in co-culture studies. While the cell responsible for suppression of $\mathrm{T}$ lymphocyte colony formation was resistant to 2,500 rad irradiation, suggestive of either a radio-resistant $\mathrm{T}$ lymphocyte or monocyte, the cell responsible for the suppression of erythropoiesis was sensitive to 2,500 rad irradiation. Therefore, this patient seems to exhibit regulatory defects involving both lymphocytes and monocytes, resulting in suppression of both erythroid and lymphoid proliferation, respectively.

Because there are indications that monocytes and lymphocytes play a role in the regulation of normal erythropoiesis (16) in addition to their important roles in the regulation of immune function, it is reasonable to assume that patients with derangements in the regulation of lymphocyte function might also demonstrate abnormalities in erythropoietic regulation. Patient E.D. would seem to fit such a categorization of a regulatory disorder.

In our three remaining patients who also showed some impairment of lymphocyte function we were however unable to demonstrate any excessive suppressor activities directed against either lymphocyte proliferation or erythropoiesis. This finding is more suggestive of an intrinsic cellular defect rather than a disturbance of cell regulation as demonstrated by patient E.D. An alternative explanation to be considered is that these four patients lack necessary helper cells required for normal erythropoiesis and lymphopoiesis. Nathan et al. (17) have demonstrated that either syngeneic or allogeneic purified $T$ lymphocytes will stimulate erythroid colony growth (BFU-E) by peripheral blood "null" cells, although they could not prove that such helper cells were an absolute requirement for erythropoiesis. In further studies, they have indicated that $T$ helper function for erythropoiesis was not deficient in their patients with congenital hypoplastic anemia (14). However, it is presently unclear whether $\mathrm{T}$ helper cells are even required for normal bone marrow, rather than peripheral blood, erythroid colony growth (18). In our own patients, addition of normal peripheral blood mononuclear cells to patients' bone marrows in erythroid cultures failed uniformly to improve the poor erythroid colony growth of the patients, arguing against a helper cell defect in our patients, and supportive of an intrinsic proliferative defect.

It should also be pointed out that the assay systems used may not be capable of detecting excessive suppressor mechanisms; if such suppression were genetically restricted, then with respect to erythropoiesis, co- culture of patient peripheral blood mononuclear cells with allogeneic normal bone marrow would not produce suppression of erythroid colony growth of the allogeneic marrow. To date, there is no evidence of genetically restricted cell-mediated suppressor mechanisms operant in either normal or deranged states of erythroid or lymphoid function in man. However, genetic restriction of virus-induced cell-mediated cytotoxicity has been implicated as a pathogenetic mechanism in some patients with aplastic anemia (19). Extrapolation of this type of mechanism to congenital hypoplastic anemia remains highly speculative.

Hoffman et al. (12) have demonstrated cell-mediated suppression of normal bone marrow erythroid colony growth (CFU-E) by peripheral blood lymphocytes from some patients with congenital hypoplastic anemia. Similarly, Steinberg et al. (13) have shown that peripheral blood lymphocytes from patients with congenital hypoplastic anemia could inhibit the erythroid colony growth (BFU-E) of both normal and patients' peripheral blood. We have recently reported our studies in a patient with monocyte-mediated suppression of erythropoiesis in association with congenital hypoplastic anemia (3). Other groups have been unable to demonstrate cell-mediated suppression of erythropoiesis in their patients with congenital hypoplastic anemia $(14,15)$. We attribute the differences in findings by various investigators to a diversity of pathogenetic mechanisms in these patients.

Our data presented here indicate that in congenital hypoplastic anemia, pathogenetic mechanisms may include regulatory defects as well as intrinsic cellular defects, involving not only the erythroid cell series, but which are reflected in studies of the immune system.

\section{ACKNOWLEDGMENTS}

This work was supported by a grant from the John A. Hartford Foundation, New York, and a grant from the National Institutes of Health (HD-07778).

\section{REFERENCES}

1. Diamond, L. K., W. C. Wang, and B. P. Alter. 1976. Congenital hypoplastic anemia. Adv. Pediatrics. 22: 349-378.

2. Alter, B. P. 1980. Childhood red cell aplasia. Am. J. Ped. Hem. Onc. 2: 121-139.

3. Finlay, J. L., N. T. Shahidi, S. Horowitz, and R. Hong. 1980. Cellular and humoral suppression of erythropoiesis in congenital hypoplastic anemia. Pediatr. Res. 14: 533. (Abstr.).

4. Ito, K., N. Sakura, T. Usui, and H. Uchino. 1977. Screening for primary immunodeficiencies associated with purine nucleoside phosphorylase deficiency or adenosine deaminase deficiency. J. Lab. Clin. Med. 90: 844-848. 
5. Jondal, M., G. Holm, and H. Wigzell. 1972. Surface markers of human T and B lymphocytes. I. A large population of lymphocytes forming non-immune rosettes with sheep red blood cells. J. Exp. Med. 136: 207-215.

6. Potter, M. R. and M. Moore. 1976. Characterization and separation of human lymphocytes forming mouse red cell rosettes. J. Immunol. Methods. 19: 125-135.

7. Winchester, R. J., S. M. Fu, T. Hoffman, and H. G. Kunkel. 1975. IgG on lymphocyte surfaces; technical problems and the significance of a third cell population. J. Immunol. 114: 1210-1212.

8. Rice, L., A. H. Laughter, and J. J. Twomey. 1979. Three suppressor systems in human blood that modulate lymphoproliferation. J. Immunol. 122: 991-996.

9. Lowenberg, B., and H. M. DeZeeuw. 1979. A method for cloning T-lymphocytic precursors in agar. Am. J. Hematol. 6: 35-43.

10. Iscove, N. N., F. Sieber, and K. H. Winterhalter. 1974. Erythroid colony formation in cultures of mouse and human bone marrow. Analysis of the requirement for erythropoietin by gel filtration and affinity chromatography on agarose-concanavalin A. J. Cell Physiol. 83: 309-320.

11. Horowitz, S., W. Borcherding, A. V. Moorthy, R. Chesney, H. Schulte-Wisserman, R. Hong, and A. Goldstein. 1977. Induction of suppressor $T$ cells in systemic lupus erythematosus by thymosin and cultured thymic epithelium. Science (W ash., DC). 197: 999-1001.

12. Hoffman, R., E. D. Zanjani, J. Vila, R. Zalusky, J. D. Lutton, and I. R. Wasserman. 1976. Diamond-Blackfan syndrome: lymphocyte-mediated suppression of erythropoiesis. Science (Wash., DC). 193: 899-900.

13. Steinberg, M. H., M. F. Coleman, and J. B. Pennebaker. 1979. Diamond-Blackfan Syndrome: Evidence for T-cell mediated suppression of erythroid development and a serum blocking factor associated with remission. $\mathrm{Br}$. J. Haematol. 41: 57-68.

14. Nathan, D. G., D. G. Hillman, L. Chess, B. P. Alter, B. J. Clarke, J. Breard, and D. E. Housman. 1978. Normal erythropoietic helper $\mathrm{T}$ cells in congenital hypoplastic (Diamond-Blackfan) anemia. N. Engl. J. Med. 298: 1049-1051.

15. Freedman, M. H., and E. F. Saunders. 1978. DiamondBlackfan syndrome: Evidence against cell-mediated erythropoietic suppression. Blood. 51: 1125-1128.

16. Rinehart, J. J., E. D. Zanjani, B. Nomdedeu, B. J. Gormus, and M. E. Kaplan. 1978. Cell-cell interaction in erythropoiesis: Role of human monocytes. J. Clin. Invest. 62: 979-986.

17. Nathan, D. G., L. Chess, D. G. Hillman, B. Clarke, J. Breard, E. Merler, and D. E. Housman. 1978. Human erythroid burst-forming unit: T-cell requirement for proliferation in vitro. J. Exp. Med. 147: 324-339.

18. Lipton, J. M., E. L. Reinherz, M. Kudisch, P. L. Jackson, S. F. Schlossman, and D. G. Nathan. 1980. Mature bone marrow erythroid burst-forming units do not require $T$ cells for induction of erythropoietin-dependent differentiation. J. Exp. Med. 152: 350-360.

19. Parkman, R. 1978. The immunopathology of marrow failure. Clin. Haematol. 7: 475-486. 